\title{
Effects of mushroom waster medium and stalk residues on the growth performance and oxidative status in broilers
}

\author{
Y. C. Hsieh ${ }^{1}$, W. C. Lin ${ }^{1}$, W. Y. Chuang ${ }^{1}$, M. H. Chen ${ }^{2}$, S. C. Chang ${ }^{3}$, and T. T. Lee ${ }^{1,4, *}$
}

\author{
* Corresponding Authors: T. T. Lee \\ Tel: +886-4-2284-0366, \\ Fax: +886-4-2286-0265, \\ E-mail: ttlee@dragon.nchu.edu.tw \\ ${ }^{1}$ Department of Animal Science, Nationa \\ Chung Hsing University, Taichung, 402, \\ Taiwan \\ 2 Taiwan Agricultural Research Institute, \\ Council of Agriculture, Executive Yuan, \\ Taichung City, 41362, Taiwan \\ ${ }^{3}$ Kaohsiung Animal Propagation Station, \\ Livestock Research Institute, Council of \\ Agriculture, Executive Yuan, Pingtung \\ 91201, Taiwan \\ ${ }^{4}$ The iEGG and Animal Biotechnology Center, \\ National Chung Hsing University, Taichung, \\ 402, Taiwan \\ ORCID \\ Y. C. Hsieh \\ https://orcid.org/0000-0003-0299-5518 \\ W. C. Lin \\ https://orcid.org/0000-0002-7476-5394 \\ W. Y. Chuang \\ https://orcid.org/0000-0002-5282-5878 \\ M. H. Chen \\ https://orcid.org/0000-0001-5706-0168 \\ S. C. Chang \\ https://orcid.org/0000-0003-1746-9481 \\ T. T. Lee \\ https://orcid.org/0000-0002-0063-5714
}

Submitted Nov 17, 2019; Revised Jan 29, 2020; Accepted Feb 21, 2020

\begin{abstract}
Objective: The study developed mushroom stalk residues as feed additives in the broiler diet for improving the growth performance and immunity of broilers as well as to increase the value of mushroom stalk residues.

Methods: In total, 300 ROSS 308 broilers were randomly allocated into fifteen pens with five dietary treatments: i) control, basal diet; ii) CMWM, supplemented with $1 \%$ Cordyceps militaris waster medium (CM); iii) CMPE, supplemented with $0.5 \% \mathrm{CM}+0.5 \%$ Pleurotus eryngii stalk residue (PE); iv) CMPS, supplemented with $0.5 \% \mathrm{CM}+0.5 \%$ Pleurotus sajorcaju stalk residue (PS); v) CMFV, supplemented with $0.5 \% \mathrm{CM}+0.5 \%$ Fammulina velutipes stalk residue (FV).

Results: The chemical analysis results showed that CM extracts, PE extracts, PS extracts, and FV extracts contain functional components such as polysaccharides and phenols and have both 2, 2-diphenyl-1-picryl-hydrazyl-hydrate scavenging and Ferrous scavenging capacities. The group CMWM saw increased body weight gain and feed conversion rate and the promotion of jejunum villus growth, but there is no significant difference in the intestinal bacteria phase. Antioxidant genes in the nuclear factor (erythroid-derived 2)-like 2 (Nrf2)- antioxidant responsive element pathway among the groups are significantly higher than that of the control group, especially in group CMWM.

Conclusion: The mushroom stalk residues have antioxidant functional components, can improve the intestinal health and body weight gain of chickens, and can activate the antioxidant pathway of Nrf2 to increase the heme oxygenase-1 expression. The treatment with $1 \% \mathrm{CM}$ was the most promising as a feed additive.
\end{abstract}

Keywords: Mushroom; Waster Medium; Stalk Residues; Broiler Chickens; Antioxidant

\section{INTRODUCTION}

Animal rearing environment will often affect animal health by crowding, temperature, and opportunistic infection with some microbes [1-4]. While these external pressures make animals use energy to resist the stress, the oxidative environment in their body also loses its balance and increases their oxidative stress, causing an oxidative chain reaction to destroy cell tissue [1]. In the face of these environmental challenges, people often choose to add trace antibiotics to animal feed, which can reduce the chance of inflammation in the intestine. If inflammation is prevented, then stress of the animal or the oxidative stress in its body will be indirectly reduced and can decrease energy lose, which can then be used in the immune system to keep it in a comfortable state and to increase productivity [5]. However, with the gradual ban of antibiotics in the EU in 2006, the world has begun to pay more and more attention to drug residues and drug-resistant bacteria. Therefore, the animal feed industry is looking for alternatives to antibiotics.

Some reactive oxygen species (ROS) can cause oxidative damage to animal organs through the properties of their free radicals [6]. Among the many functional components contained 
in mushrooms, like phenolic compounds, triterpenoids have strong anti-oxidation ability. Studies have shown that triterpenoids have the function of preventing oxidative damage caused by free radicals and can prevent or delay the onset of disease [7]. Some studies have also indicated that phenolic compounds have the ability to reduce lipid oxidation [8]. Previous studies found that Cordyceps militaris has components such as cordycepin, phenolic compounds, adenosine, and various polysaccharides [9], which are believed to activate macrophages via the nuclear factor- $\kappa B$ pathway and promote the performance of major histocompatibility complex molecules enhancing the ability of antigen presentation [10].

Studies have also shown that Pleurotus eryngii has many functional ingredients, such as phenols and polysaccharides, which have antioxidant properties and improve the meat quality of broilers [11]. Pleurotus eryngii can also improve the performance of laying hens as well as the egg quality and antioxidant capacity of eggs [12]. In addition, there are also references to bactericidal activity and serum immune responses [13]. Pleurotus sajor-caju has a similar nutritional composition to Pleurotus ostreatus and presents antioxidant activity [14]. Pleurotus sajor-caju stalk residue (PS) has also been shown to have antibacterial activity against gram-positive and gram-negative bacteria [15]. Fammulina velutipes is believed to be effective at improving the health of laying hens and has been shown to improve egg integrity and increase calcium in eggshells in laying hens [16].

After a culture is completed, the fruiting bodies are sold, but the culture medium and stalk residues are treated as waste. These white-rot fungus wastes have been proven to improve the production performance of laying hens [17]. Nevertheless, the literature has rarely compared the use of different stalk residues in feed. Thus, the purpose of this experiment is to investigate whether different combinations of mushroom stalk residues as feed additives can improve the health and performance of broilers.

\section{MATERIALS AND METHODS}

The Cordyceps militaris waster medium (CM), Pleurotus eryngii stalk residues (PE), Pleurotus sajor-caju stalk residues (PS), and Fammulina velutipes stalk residues (FV) in this study were taken from Taiwan's Agricultural Research Institute, COA. The mushroom stalk residues were extracted with distilled water $(1: 10, \mathrm{w} / \mathrm{v})$ at $95^{\circ} \mathrm{C}$ for 2 hours and filtered with a filter paper (Advantec No. 1, Tokyo, Japan). The filtrate was used for subsequent analysis.

\section{2, 2-Diphenyl-1-picryl-hydrazyl-hydrate radical} scavenging capacity (\%)

The experiment prepared Tris-Hcl (pH 4.7, 100 mM) buffer and ethanol solution containing $250 \mu \mathrm{M}$ 2, 2-diphenyl-1picryl-hydrazyl-hydrate (DPPH), mixed $100 \mu \mathrm{L}$ samples of different concentrations and $400 \mu \mathrm{L}$ of the above buffer, added $500 \mu \mathrm{L}$ of the above DPPH solution, and let stand for $20 \mathrm{~min}$ utes in the dark. Absorbance was measured at $517 \mathrm{~nm}$, and ethanol was used as a control. A lower absorbance value of the reaction mixture indicated a stronger scavenge effect and was calculated by DPPH scavenging effects $(\%)=(1-[\mathrm{A} 1 /$ $\mathrm{A} 0]) \times 100 \%$, in which $\mathrm{A} 1$ is the net absorbance in the presence of the sample (the sample measured absorbance - background absorbance), and A0 is the absorbance of the control reaction (ethanol) [18].

\section{Ferrous scavenging capacity (\%)}

The experiment prepared $\mathrm{FeCl} 2$ (ferrous chloride $\cdot 4 \mathrm{H}_{2} \mathrm{O}, 2$ $\mathrm{mM}$ ) and ferrozine ( $5 \mathrm{mM})$, added $0.25 \mathrm{~mL}$ of different concentrations of the sample to $0.8 \mathrm{~mL}$ of deionized water and $0.025 \mathrm{~mL}$ of $2 \mathrm{mM} \mathrm{FeCl}_{2}$, and then added $0.05 \mathrm{~mL}$ of $5 \mathrm{mM}$ Ferrozine solution at room temperature for 30 seconds. After 10 minutes of reaction, the absorbance was measured at 562 $\mathrm{nm}$, and $0.25 \mathrm{~mL}$ of deionized water was used as a control. A lower absorbance value of the reaction mixture indicated a stronger scavenge effect and was calculated by Ferrous ion chelating $(\%)=(1-[\mathrm{A} 1 / \mathrm{A} 0]) \times 100 \%$, in which $\mathrm{A} 1$ is the net absorbance in the presence of the sample (the sample measured absorbance - background absorbance), and A0 is the absorbance of the control reaction (deionized water) [19].

\section{Animal experimental design}

The experimental animals and breeding environment were approved by National Chung Hsing University, Taiwan (IACUC: 107-043). Three hundred ROSS 308 female broilers were selected and separated into five treatment groups: control group, $1 \%$ golden Cordyceps militaris waster medium group (CMWM), 0.5\% CM + 0.5\% PE group (CMPE), 0.5\% $\mathrm{CM}+0.5 \%$ PS group (CMPS), and $0.5 \% \mathrm{CM}+0.5 \% \mathrm{FV}$ group (CMFV). Each treatment was repeated three times of 20 broilers per replications (a total of 60 birds/treatment). The broilers were kept in a temperature-controlled house, and the temperature was controlled at $27^{\circ} \mathrm{C} \pm 2^{\circ} \mathrm{C}$. The broilers within 1 to 7 day-old were kept warm by fences and heater lamps. The field was a concrete floor $(2.5 \mathrm{~m} \times 4 \mathrm{~m})$ with rice bran. Two feed drinkers and one feed tray were installed in each field in the first 21 days; the nipple drinker and feed trough were replaced every 22 to 35 days. A vaccine for Newcastle disease and infectious bronchitis was provided via the nose when the broilers were one day old. The form of feed formula was formulated according to the nutritional requirements of broilers [20] and contained no coccidia and antibiotics (Tables 1,2). The lighting program was based on Ramlucken et al [21], the broilers were exposed to $23 \mathrm{~h}$ of light up to $7 \mathrm{D}$ of age, and then from there onwards they 
Table 1. Composition and calculated analysis ( $\mathrm{g} / \mathrm{kg}$ as fed) of the basal diet for broilers (1 to 21 days)

\begin{tabular}{|c|c|c|c|c|c|}
\hline Items & Control $^{1)}$ & CMWM $^{1)}$ & $\mathrm{CMPE}^{1)}$ & CMPS $^{1)}$ & CMFV $^{1)}$ \\
\hline \multicolumn{6}{|l|}{ Ingredients } \\
\hline Yellow corn & 488.7 & 472.3 & 474.7 & 474.9 & 473.3 \\
\hline Soybean meal (CP 44.0\%) & 345.2 & 330.0 & 314.5 & 330.1 & 332.0 \\
\hline Full fat soybean meal & 83.6 & 103.2 & 120.0 & 100.7 & 100.0 \\
\hline Soybean oil & 35.3 & 37.3 & 33.6 & 37.1 & 37.5 \\
\hline Calcium carbonate & 16.2 & 16.2 & 16.2 & 16.2 & 16.2 \\
\hline Monocalcium phosphate & 18.6 & 18.6 & 18.6 & 18.6 & 18.6 \\
\hline DL-methionine & 2.0 & 2.0 & 2.0 & 2.0 & 2.0 \\
\hline L-lysine-HCl & 3.7 & 3.7 & 3.7 & 3.7 & 3.7 \\
\hline $\mathrm{NaCl}$ & 3.9 & 3.9 & 3.9 & 3.9 & 3.9 \\
\hline Choline-Cl (50\%) & 0.8 & 0.8 & 0.8 & 0.8 & 0.8 \\
\hline Vitamin premix ${ }^{2)}$ & 1.0 & 1.0 & 1.0 & 1.0 & 1.0 \\
\hline Mineral premix ${ }^{3)}$ & 1.0 & 1.0 & 1.0 & 1.0 & 1.0 \\
\hline CM & - & 10.0 & 5.0 & 5.0 & 5.0 \\
\hline PE & - & - & 5.0 & - & - \\
\hline PS & - & - & - & 5.0 & - \\
\hline FV & - & - & - & - & 5.0 \\
\hline Total & 1,000 & 1,000 & 1,000 & 1,000 & 1,000 \\
\hline \multicolumn{6}{|l|}{ Calculated nutrient value } \\
\hline ME (kcal/kg) & $3,050.0$ & $3,050.0$ & $3,050.0$ & $3,050.1$ & $3,050.1$ \\
\hline $\mathrm{CP}(\% \mathrm{DM})$ & 23.0 & 23.0 & 23.0 & 23.0 & 23.0 \\
\hline Calcium (\% DM) & 1.05 & 1.05 & 1.05 & 1.05 & 1.05 \\
\hline Total phosphorus (\% DM) & 0.76 & 0.76 & 0.76 & 0.76 & 0.76 \\
\hline Available phosphorus, (\% DM) & 0.52 & 0.52 & 0.52 & 0.52 & 0.52 \\
\hline Lysine (\% DM) & 1.54 & 1.54 & 1.54 & 1.54 & 1.54 \\
\hline Methionine+cystein (\% DM) & 0.90 & 0.90 & 0.90 & 0.90 & 0.90 \\
\hline \multicolumn{6}{|l|}{ Analyzed nutrient value } \\
\hline Crude protein (\% DM) & 23.0 & 22.9 & 22.9 & 23.1 & 23.2 \\
\hline Crude fat (\% DM) & 6.6 & 6.8 & 7.1 & 7.2 & 6.9 \\
\hline
\end{tabular}

$\mathrm{CP}$, crude protein; $\mathrm{CM}$, Cordyceps militaris waster medium; PE, Pleurotus eryngii stalk residues; PS, Pleurotus sajor-caju stalk residues; FV, Fammulina velutipes stalk residues; $\mathrm{CP}$, crude protein; $\mathrm{ME}$, metabolizable energy; DM, dry matter.

1) Control, basal diet; CMWM, basal diet supplemented with 1\% CM; CMPE, basal diet supplemented with 0.5\% CM+0.5\% PE; CMPS, basal diet supplemented with $0.5 \% \mathrm{CM}+0.5 \% \mathrm{PS}$; CMFV, basal diet supplemented with $0.5 \% \mathrm{CM}+0.5 \% \mathrm{FV}$.

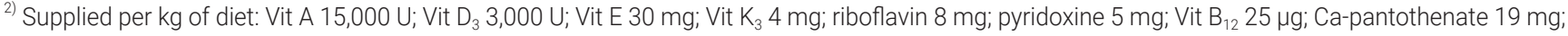
niacin $50 \mathrm{mg}$; folic acid $1.5 \mathrm{mg}$; biotin $60 \mu \mathrm{g}$.

3) Supplied per kg of diet: Co 0.255 mg; Cu 10.8 mg; Fe 90 mg; Zn 68.4 mg; Mn 90 mg; Se0.18 mg.

received $8 \mathrm{~h}$ of darkness continuously in a 24 -h period. The experimental materials and feed composition were analyzed according to AOAC [22].

\section{Performance and serum intestinal content collection}

The experiment collected the weights of broilers at the ages of 1,21 , and 35 days, and feed consumption was recorded at 21 and 35 days of age. The calculated data included body weight gain, feed intake, and feed conversion rate (FCR) of the birds. At 35 days of age, 4 broilers were randomly selected from each cage, and 2 of them had $5 \mathrm{~mL}$ of blood collected from the wing vein by a heparin anticoagulation tube for detection of quantitative real-time polymerase chain reaction (RT-PCR). The other two broilers were euthanized by electric shock, and the contents of ileum and cecum were removed from the lower abdomen to detect intestinal flora.

\section{Microbial populations in ileal and cecal contents}

The experiment collected fresh ileum and cecum contents, put $1 \mathrm{~g}$ of chyme into $9 \mathrm{~mL}$ deionized water, and measured the $\mathrm{pH}$ value by a $\mathrm{pH}$ meter. One $\mathrm{g}$ of chyme was put into 9 $\mathrm{mL}$ phosphate-buffered saline (PBS) and the sequence dilution for the microbial parameter. The amount of bacteria after dropping $0.1 \mathrm{~mL}$ of the bacteria into an appropriate medium and smearing them was counted. Coliform was cultured in aerobic $37^{\circ} \mathrm{C}$ for 24 hours with chromogenic medium agar (CHROagar ECC, Springfield, NJ, USA); Lactobacillus spp. were cultured at anaerobic $37^{\circ} \mathrm{C}$ for 48 hours with De Man, Rogosa and Sharpe agar (Difco Lactobacilli MRS Agar, Franklin Lakes NJ, USA); and Clostridium perfringens was cultured for 48 hours with tryptose sulfite cycloserine agar (GranuCult TSCagar, Merck, Kenilworth, NJ, USA) at anaerobic $37^{\circ} \mathrm{C}$. After culturing, the number of colony-forming unit (CFU) on the agar was counted. 
Table 2. Composition and calculated analysis ( $\mathrm{g} / \mathrm{kg}$ as fed) of the basal diet for broilers (22 to 35 days)

\begin{tabular}{|c|c|c|c|c|c|}
\hline Items & Control $^{1)}$ & CMWM $^{1)}$ & $\mathrm{CMPE}^{1)}$ & CMPS $^{1)}$ & CMFV $^{1)}$ \\
\hline \multicolumn{6}{|l|}{ Ingredient } \\
\hline Yellow corn & 536.0 & 522.8 & 523.0 & 523.0 & 523.0 \\
\hline Soybean meal (CP 44.0\%) & 280.8 & 263.8 & 291.4 & 291.5 & 291.5 \\
\hline Full fat soybean meal & 100.0 & 117.3 & 86.0 & 86.0 & 86.0 \\
\hline Soybean oil & 42.1 & 45.0 & 48.5 & 48.4 & 48.4 \\
\hline Calcium carbonate & 13.4 & 13.4 & 13.4 & 13.4 & 13.4 \\
\hline L-lysine- $\mathrm{HCl}$ & 3.2 & 3.2 & 3.2 & 3.2 & 3.2 \\
\hline $\mathrm{NaCl}$ & 3.8 & 3.8 & 3.8 & 3.8 & 3.8 \\
\hline Choline-Cl (50\%) & 0.8 & 0.8 & 0.8 & 0.8 & 0.8 \\
\hline Vitamin premix ${ }^{2)}$ & 1.0 & 1.0 & 1.0 & 1.0 & 1.0 \\
\hline Mineral premix ${ }^{3)}$ & 1.0 & 1.0 & 1.0 & 1.0 & 1.0 \\
\hline Total & 1,000 & 1,000 & 1,000 & 1,000 & 1,000 \\
\hline \multicolumn{6}{|l|}{ Calculated nutrient value } \\
\hline $\mathrm{ME}(\mathrm{kcal} / \mathrm{kg})$ & $3,173.63$ & $3,173.65$ & $3,173.63$ & $3,173.63$ & $3,173.64$ \\
\hline Crude protein (\% DM) & 21.01 & 21.01 & 21.01 & 21.01 & 20.01 \\
\hline Calcium (\% DM) & 0.89 & 0.89 & 0.89 & 0.89 & 0.89 \\
\hline Total phosphorus (\% DM) & 0.70 & 0.70 & 0.70 & 0.70 & 0.70 \\
\hline Available phosphorus (\% DM) & 0.47 & 0.47 & 0.47 & 0.47 & 0.47 \\
\hline Lysine (\% DM) & 1.38 & 1.38 & 1.37 & 1.37 & 1.37 \\
\hline Methionine+cysteine (\% DM) & 0.79 & 0.78 & 0.78 & 0.78 & 0.78 \\
\hline \multicolumn{6}{|l|}{ Analyzed nutrient value } \\
\hline Crude protein (\% DM) & 21.1 & 20.9 & 21 & 21.2 & 21.1 \\
\hline
\end{tabular}

CM, Cordyceps militaris waster medium; PE, Pleurotus eryngii stalk residues; PS, Pleurotus sajor-caju stalk residues; FV, Fammulina velutipes stalk residues; $\mathrm{CP}$, crude protein; ME, metabolizable energy; DM, dry matter.

1) Control, basal diet; CMWM, basal diet supplemented with 1\% CM; CMPE, basal diet supplemented with 0.5\% CM+0.5\% PE; CMPS, basal diet supplemented with $0.5 \% \mathrm{CM}+0.5 \% \mathrm{PS}$; CMFV, basal diet supplemented with $0.5 \% \mathrm{CM}+0.5 \% \mathrm{FV}$.

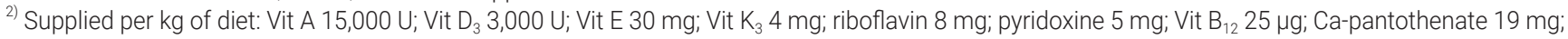
niacin $50 \mathrm{mg}$; folic acid $1.5 \mathrm{mg}$; biotin $60 \mu \mathrm{g}$.

3) Supplied per kg of diet: Co 0.255 mg; Cu 10.8 mg; Fe 90 mg; Zn 68.4 mg; Mn 90 mg; Se 0.18 mg.

\section{Intestinal morphology}

At the age of 35 days, 4 broilers were randomly selected from each column to be euthanized by electric shock. The jejunum (the bile duct junction to the Merkel ventricle) and the ileum (the Merkel ventricle to the cecum junction) were removed from the lower abdomen. The contents of the intestines were carefully washed away in $3 \mathrm{~cm}$ with a PBS solution, cut into small pieces, and placed in $10 \%$ formalin for fixation. After standing for 5 days, they were entrusted to the Department of Veterinary Medicine, National Chung Hsing University, Taiwan for paraffin embedding, sectioning, and staining. Intestinal sections were observed using an optical microscope, the villus height, crypt depth, and muscle layer thickness were measured with a Motic Image Plus 2.0 analysis system (Motic Instruments, Richmond, Canada), and the villus height and crypt depth ratio were calculated.

\section{Quantitative real-time polymerase chain reaction}

After centrifuging fresh blood, it was aspirated with supernatant and PBS was added to the original volume. After slowly shaking, $3 \mathrm{~mL}$ of the mixture was pipetted into $3 \mathrm{~mL}$ of Ficol and centrifuged at $200 \mathrm{~g}$ for 30 minutes. A middle layer of peripheral blood mononuclear cell (PBMC) was taken to a new centrifuge tube and $3 \mathrm{~mL}$ of PBS was added; mix and centrifuge to remove the supernatant and scrape off the precipitated blood cells, add $3 \mathrm{~mL}$ of PBS, mix and centrifuge, and discard the supernatant. The number of precipitated blood cells was calculated and added back to the volume of PBS. Next, $20 \mu \mathrm{L}$ of the dye was extracted, and the blood cells were mixed in equal amounts. After counting the number of cells, reconstituted the Roswell Park Memorial Institute (RPMI) medium and adjusted the number of cells to $1 \times 10^{7}$ cells $/ \mathrm{mL}$. The mRNA in PBMC was extracted with a Directzol RNA miniprep kit and modified according to the method 
of Yamaguchi et al [23]. The mRNA was reverse transcribed into CDNA, and its concentration was measured by qPCR. $\mathrm{B}$-actin was used as a standard for all genes and was calculated by the method of $2^{-\Delta \Delta \mathrm{Ct}}$. All the primer sequences are shown in Table 3.

\section{Statistical analysis}

All data were employed by SAS (SAS 9.4, 2018) statistical software and analyzed by analysis of variance for the completely randomized design using the general linear model program. Determination of differences between the mean values of the groups was conducted by Tukey. The differences between the treatments were compared by the $\mathrm{p}<0.05$.

\section{RESULTS}

\section{Component analysis}

Table 4 presents the analysis of the chemical composition and the bioactive compounds of CM, PE, PS, and FV. CM contained $97.3 \%$ dry matter, $1.23 \%$ ash, $7.8 \%$ crude protein, 63.1\% neutral detergent fiber (NDF), 8.0\% acid detergent fiber (ADF) and 3.84\% crude fat; PE contained $94.5 \%$ dry matter, $5.91 \%$ ash, $17.21 \%$ crude protein, $57.9 \%$ NDF, $7.4 \% \mathrm{ADF}$ and $6.39 \%$ crude fat; PS contained $97.9 \%$ dry matter, $6.77 \%$ ash, 22.43\% crude protein, $61.9 \% \mathrm{NDF}, 8.2 \% \mathrm{ADF}$ and $2.01 \%$ crude fat; FV contained $93.0 \%$ dry matter, $11.54 \%$ ash, $12.65 \%$ crude protein, $60.8 \% \mathrm{NDF}, 8.0 \% \mathrm{ADF}$ and $5.04 \%$ crude fat. The polysaccharide content of the CM was the highest, be-

Table 3. Primers used for q-PCR analysis

\begin{tabular}{|c|c|c|c|}
\hline Gene & $\begin{array}{l}\text { Forward primer (from 5' to } 3^{\prime} \text { ) } \\
\text { Reverse primer (from 5' to } 3^{\prime} \text { ) }\end{array}$ & PCR product size (bp) & Accession in GenBank \\
\hline$\beta$-actin & $\begin{array}{l}\text { CTGGCACCTAGCACAATGAA } \\
\text { ACATCTGCTGGAAGGTGGAC }\end{array}$ & 109 & X00182.1 \\
\hline Keap1 & $\begin{array}{l}\text { ATGGCCACACTTTTCTGGAC } \\
\text { ATCAATTTGCTTCCGACAGG }\end{array}$ & 137 & AB020063.1 \\
\hline Nrf2 & $\begin{array}{l}\text { GGAAGAAGGTGCGTTTCGGAGC } \\
\text { GGGCAAGGCAGATCTCTTCCAA }\end{array}$ & 171 & NM_205117.1 \\
\hline $\mathrm{HO}-1$ & $\begin{array}{l}\text { AGCTTCGCACAAGGAGTGTT } \\
\text { GGAGAGGTGGTCAGCATGTC }\end{array}$ & 106 & X56201.1 \\
\hline GCLC & $\begin{array}{l}\text { CAGCACCCAGACTACAAGCA } \\
\text { CTACCCCCAACAGTTCTGGA }\end{array}$ & 118 & XM_419910.3 \\
\hline NOX1 & $\begin{array}{l}\text { CAATGCAGCACTCCACTTTG } \\
\text { GACAAGATCTCCGCAAGACC }\end{array}$ & 185 & NM_001101830.1 \\
\hline ROMO1 & $\begin{array}{l}\text { AGCCCAGCTGCTTCGACAGAGT } \\
\text { CGTCCTCTCATGCCGATCCTGA }\end{array}$ & 115 & NM_001198821.1 \\
\hline
\end{tabular}

q-PCR, quantitative polymerase chain reaction; Keap1, Kelch like ECH associated protein 1; Nrf2, nuclear factor (erythroid-derived 2)-like 2; HO-1, heme oxygenase -1; GCLC, glutamate cysteine ligase catalytic subunit; NOX1, NADPH oxygenase 1; ROMO1, reactive oxygen species modulator protein 1.

Table 4. Chemical composition and content of the bioactive compounds of mushroom stalk residues

\begin{tabular}{|c|c|c|c|c|}
\hline \multirow{2}{*}{ Items } & \multicolumn{4}{|c|}{ Stalk residues } \\
\hline & CM & PE & PS & FV \\
\hline \multicolumn{5}{|l|}{ Chemical composition } \\
\hline Dry matter (\%) & $97.3 \pm 0.3$ & $94.5 \pm 0.3$ & $97.9 \pm 0.3$ & $93.0 \pm 0.4$ \\
\hline Ash (\% DM) & $1.2 \pm 0.02$ & $5.9 \pm 0.01$ & $6.8 \pm 0.01$ & $11.5 \pm 0.01$ \\
\hline Crude protein (\%DM) & $7.8 \pm 0.08$ & $17.2 \pm 0.11$ & $22.4 \pm 0.1$ & $12.7 \pm 0.08$ \\
\hline NDF (\%DM) & $63.1 \pm 1.8$ & $57.9 \pm 1.5$ & $61.9 \pm 1.4$ & $60.8 \pm 1.0$ \\
\hline ADF (\%DM) & $8.0 \pm 0.35$ & $7.4 \pm 0.25$ & $8.2 \pm 0.41$ & $8.0 \pm 0.65$ \\
\hline Crude fat (\%DM) & $3.8 \pm 0.49$ & $6.4 \pm 0.54$ & $2.0 \pm 0.39$ & $5.0 \pm 0.57$ \\
\hline \multicolumn{5}{|l|}{ Bioactive compounds } \\
\hline Polysaccharide (mg/g) & $72.4 \pm 3.6$ & $8.2 \pm 2.2$ & $8.8 \pm 2.3$ & $5.7 \pm 0.3$ \\
\hline Total triterpenes $(\mathrm{mg} / \mathrm{g})$ & $1.2 \pm 0.1$ & $3.1 \pm 0.7$ & $3.9 \pm 1.1$ & $6.1 \pm 0.5$ \\
\hline Total phenolics (mg GAE/g DW) & $7.1 \pm 0.6$ & $14.9 \pm 1.0$ & $9.8 \pm 0.3$ & $18.1 \pm 0.5$ \\
\hline Total Flavonoid (mg QE/g DW) & $7.1 \pm 0.3$ & $10.6 \pm 0.3$ & $4.7 \pm 0.3$ & $13.8 \pm 0.1$ \\
\hline
\end{tabular}

The value is expressed as the mean \pm standard deviation $(n=5)$.

CM, Cordyceps militaris waster medium; PE, Pleurotus eryngii stalk residues; PS, Pleurotus sajor-caju stalk residues; FV, Fammulina velutipes stalk residues; DM, dry matter; GAE, gallic acid equivalent; DW, dry weight; QE, quercetin equivalent. 
cause the cultivation substrate was brown rice, which was much higher than other test materials. The content of total triterpenoids was highest in the content of FV, followed by PS and PE.

\section{2, 2-Diphenyl-1-picryl-hydrazyl-hydrate radical scavenging capacity}

The DPPH radicals' scavenging capacity of four different mushroom waster medium or stalk residues are shown in Figure 1A. The scavenging capacity of the DPPH free radical was as good as that of butylated hydroxytoluene. The results show that DPPH radicals' scavenging capacity of CM, PE, $\mathrm{PS}$, and $\mathrm{FV}$ at $10 \mathrm{mg} / \mathrm{mL}$ reached $34.2 \%, 31.2 \%, 23.2 \%$, and $27.5 \%$, respectively.

\section{Ferrous scavenging capacity}

The Ferrous scavenging capacity of four different mushroom waster medium or stalk residues are shown in Figure 1B. The Ferrous scavenging capacity was as good as that of ethylenediaminetetraacetic acid. The results show that the Ferrous scavenging capacity of CM, PE, PS, and FV at $10 \mathrm{mg} / \mathrm{mL}$ reached $91.5 \%, 70.4 \%, 68.0 \%$, and $79.4 \%$, respectively.

\section{Growth performances}

Table 5 lists the effects of four different mushroom waster medium or stalk residues on growth performance in broilers at 35 days. The feed intake and body weight gain of the CMPE and CMPS groups were lower than other groups $(\mathrm{p}<0.05)$ from days 1 to 21 . In the late feeding period ( 22 to $35 \mathrm{~d}$ ), the CMPE group had the best FCR and the lowest feed intake. The group CMWM had the highest body weight gain $(\mathrm{p}<0.05)$,

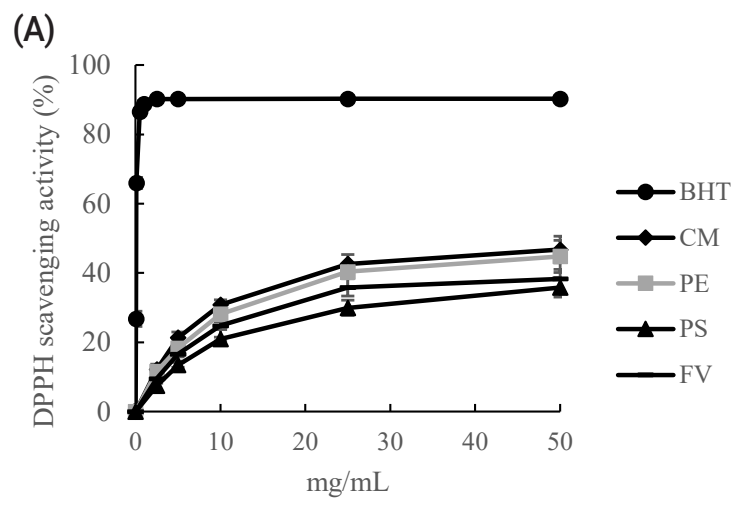

(B)

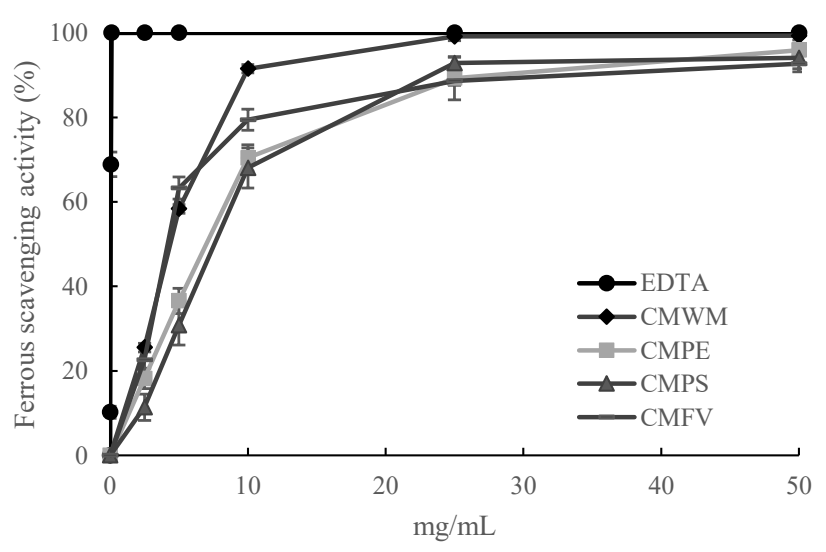

Figure 1. In vitro antioxidant assay of Cordyceps militaris waster medium (CM); Pleurotus eryngii stalk residues (PE); Pleurotus sajor-caju stalk residues (PS); Fammulina velutipes stalk residues (FV). (A) 2, 2 diphenyl-1-picryl-hydrazyl-hydrate (DPPH) scavenging capacity (B) Ferrous scavenging capacity. Values are meanıstandard deviation.

Table 5. Effects of mushroom stalk residues supplemented in diet on growth performance of broilers

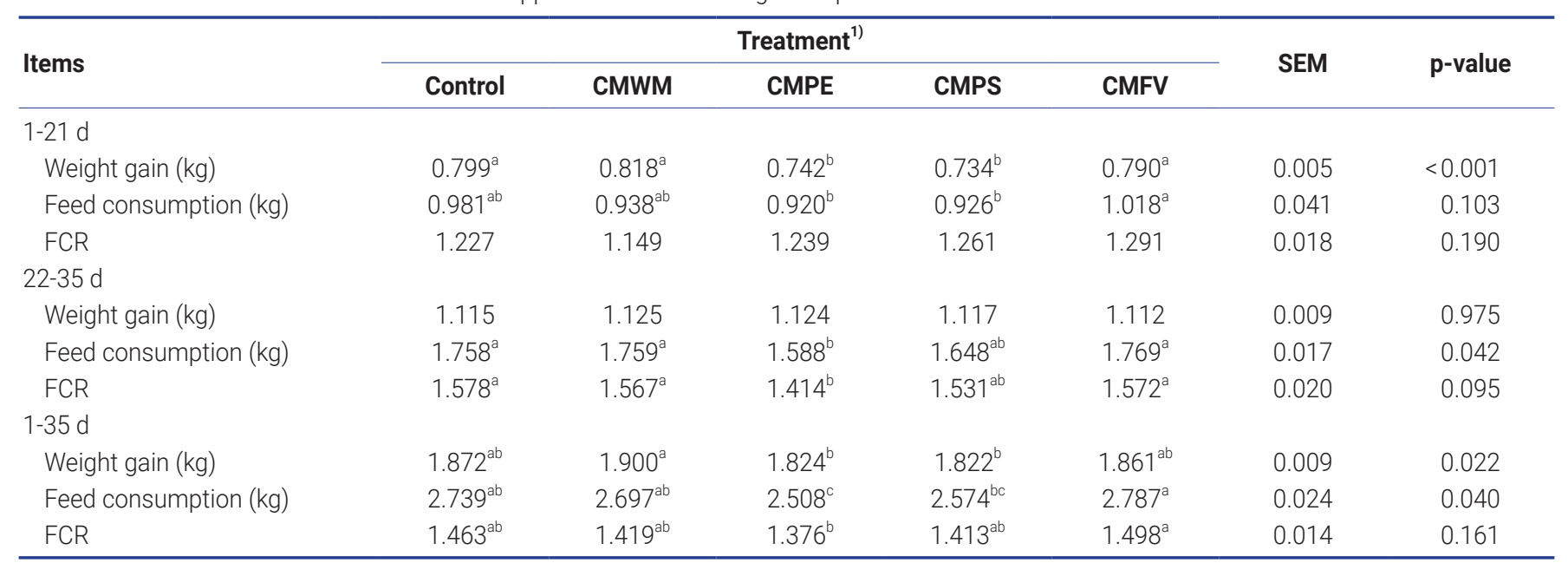

SEM, standard error of the mean; FCR, feed conversion rate.

1) Control, basic feed; CMWM, $1 \%$ Cordyceps militaris waster medium; CMPE, 0.5\% Cordyceps militaris waster medium+0.5\% Pleurotus eryngii stalk residues; CMPS, 0.5\% Cordyceps militaris waster medium+0.5\% Pleurotus sajor-caju stalk residues; CMFV, 0.5\% Cordyceps militaris waster medium+0.5\% Fammulina velutipes stalk residues.

${ }^{a-c}$ Means within the same row without common superscripts differ significantly $(p<0.05)$ 
and the CMPE group had the lowest feed intake and the best FCR $(\mathrm{p}<0.05)$ from days 1 to 35.

\section{Microbial population in ileum and ceca}

Table 6 lists the effects of four different mushroom waster medium or stalk residues on the microbial population in ileum and ceca of broilers. The group CMFV was increased by 0.2 and $0.16 \log \mathrm{CFU} / \mathrm{g}$ in the ileum and cecum, respectively, for lactic acid bacteria, but there was no significant difference in general. The group CMWM reduced the specific microbial in ileum and cecum at 0.48 and $0.18 \log$ CFU/g, respectively, compared with the control group of E. coli, but there was still no significant difference.

\section{Intestinal morphology}

Table 7 lists the effects of four different mushroom waster medium or stalk residues on the intestinal morphology of broilers. The CMPE and the CMFV groups reduced the depth of jejunum crypt compared with the control group, while the group CMWM had significantly reduced jejunum crypt depth than the other groups. In the results of jejunum villus height and crypt depth ratio, the CMWM and the CMPE groups were significantly higher than the control group.

\section{The mRNA expression level}

Figure 2 illustrates the results of the mRNA expression level in chicken PBMCs. Compared with the control group, the mRNA expressions of Kelch like ECH associated protein 1 (Keap1), nuclear factor (erythroid-derived 2)-like 2 (Nrf2), heme oxygenase-1 (HO-1), and glutamate-cysteine ligase catalytic (GCLC) in the treatment groups were significantly higher. In the mRNA expression of Nrf2, the group CMWM was significantly higher than the group CMPS and the CMFV group. There were no significant differences between the groups in NOX-1, ROMO-1, and immunomodulatory genes.

Table 6. Effects of mushroom stalk residues supplemented in diet on microbial parameter in intestinal content of broilers (day 35)

\begin{tabular}{|c|c|c|c|c|c|c|c|}
\hline \multirow{2}{*}{$\begin{array}{l}\text { Microbial parameter } \\
\quad(\log \text { CFU/g) }\end{array}$} & \multicolumn{5}{|c|}{ Treatment $^{1)}$} & \multirow{2}{*}{ SEM } & \multirow{2}{*}{ p-value } \\
\hline & Control & CMWM & CMPE & CMPS & CMFV & & \\
\hline \multicolumn{8}{|l|}{ Lactobacillus spp. } \\
\hline Caecum & 8.33 & 8.48 & 8.37 & 8.35 & 8.49 & 0.026 & 0.198 \\
\hline \multicolumn{8}{|l|}{ Coliform } \\
\hline Ileum & 7.47 & 6.99 & 7.20 & 7.00 & 7.18 & 0.029 & 0.339 \\
\hline \multicolumn{8}{|l|}{ Clostridium perfringens } \\
\hline Ileum & 6.93 & 6.75 & 7.15 & 7.07 & 7.05 & 0.060 & 0.332 \\
\hline Caecum & 9.19 & 9.05 & 9.30 & 8.88 & 8.87 & 0.027 & 0.361 \\
\hline
\end{tabular}

SEM, standard error of the mean; CFU, colony-forming unit.

${ }^{1)}$ Control, basic feed; CMWM, $1 \%$ Cordyceps militaris waster medium; CMPE, 0.5\% Cordyceps militaris waster medium+0.5\% Pleurotus eryngii stalk residues; CMPS, $0.5 \%$ Cordyceps militaris waster medium+0.5\% Pleurotus sajor-caju stalk residues; CMFV, 0.5\% Cordyceps militaris waster medium+0.5\% Fammulina velutipes stalk residues.

Table 7. Effects of mushroom stalk residues supplemented in diet on intestinal morphology of broilers (day 35)

\begin{tabular}{|c|c|c|c|c|c|c|c|}
\hline \multirow{2}{*}{ Items } & \multicolumn{5}{|c|}{ Treatment $^{1)}$} & \multirow{2}{*}{ SEM } & \multirow{2}{*}{ p-value } \\
\hline & Control & CMWM & CMPE & CMPS & CMFV & & \\
\hline \multicolumn{8}{|l|}{ Jejunum } \\
\hline Villus height $(\mu \mathrm{m})$ & $1,237.1$ & $1,240.3$ & $1,323.4$ & $1,343.9$ & $1,292.1$ & 19.4 & 0.300 \\
\hline Crypt depth $(\mu \mathrm{m})$ & $214.5^{\mathrm{a}}$ & $177.1^{\mathrm{C}}$ & $188.9^{\mathrm{bc}}$ & $203.7^{\mathrm{ab}}$ & $193.8^{\mathrm{bc}}$ & 2.67 & $<0.01$ \\
\hline Tunica muscularis $(\mu \mathrm{m})$ & 262.8 & 247.4 & 246.0 & 259.8 & 264.1 & 3.74 & 0.372 \\
\hline Villus:crypt & $6.18^{b}$ & $7.40^{\mathrm{a}}$ & $7.21^{\mathrm{a}}$ & $6.81^{\mathrm{ab}}$ & $6.99^{\mathrm{ab}}$ & 0.12 & 0.03 \\
\hline \multicolumn{8}{|l|}{ Ileum } \\
\hline Villus height ( $\mu \mathrm{m})$ & $1,040.9$ & 994.5 & 993.6 & $1,018.7$ & 997.1 & 9.55 & 0.447 \\
\hline Crypt depth ( $\mu \mathrm{m})$ & 167.2 & 153.2 & 170.8 & 155.9 & 168.3 & 2.97 & 0.228 \\
\hline Tunica muscularis $(\mu \mathrm{m})$ & 279.7 & 262.3 & 267.5 & 260.7 & 264.6 & 4.78 & 0.737 \\
\hline Villus:crypt & 6.52 & 6.94 & 6.19 & 6.77 & 6.08 & 0.13 & 0.167 \\
\hline
\end{tabular}

SEM, standard error of the mean.

1) Control, basic feed; CMWM, $1 \%$ Cordyceps militaris waster medium; CMPE, 0.5\% Cordyceps militaris waster medium+0.5\% Pleurotus eryngii stalk residues; CMPS, 0.5\% Cordyceps militaris waster medium+0.5\% Pleurotus sajor-caju stalk residues; CMFV, 0.5\% Cordyceps militaris waster medium+0.5\% Fammulina velutipes stalk residues.

${ }^{a-c}$ Means within the same row without common superscripts differ significantly $(p<0.05)$. 
(A)

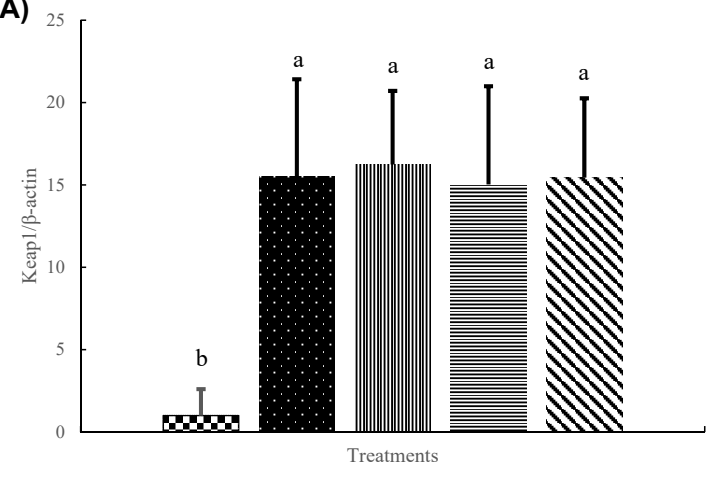

(C)

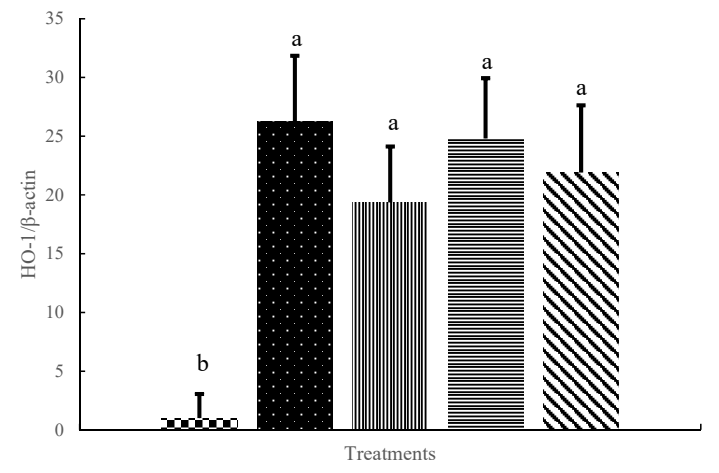

(E)

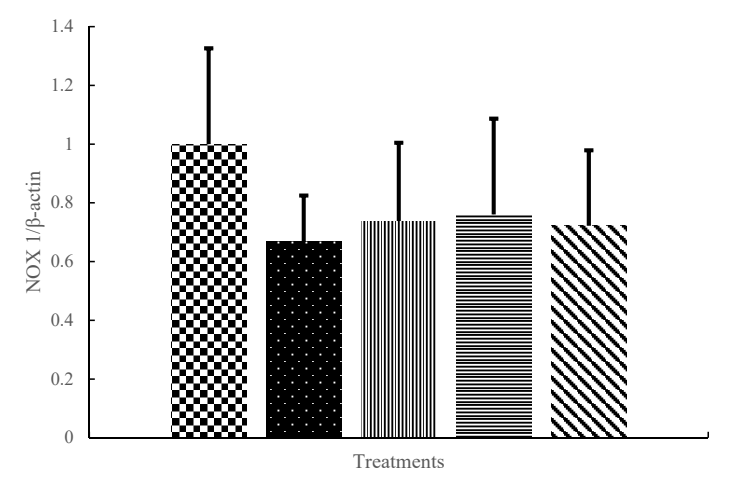

(B)
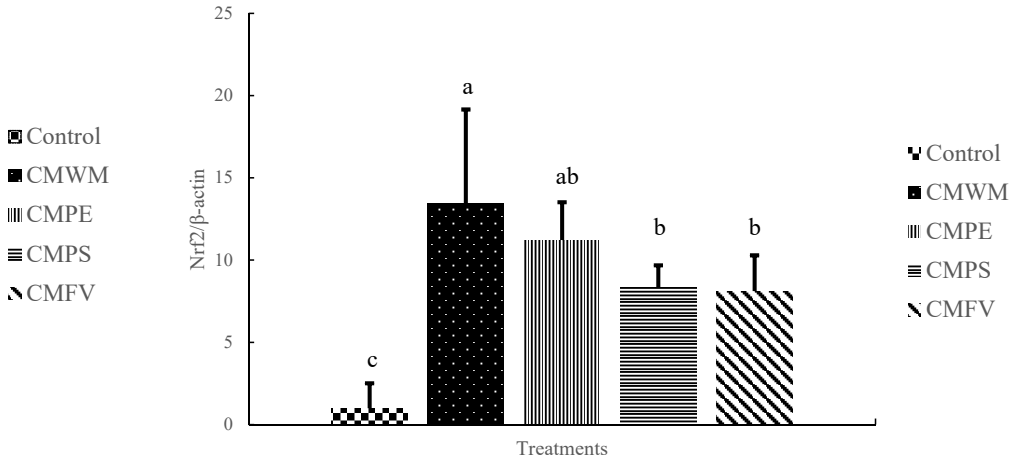

(D)
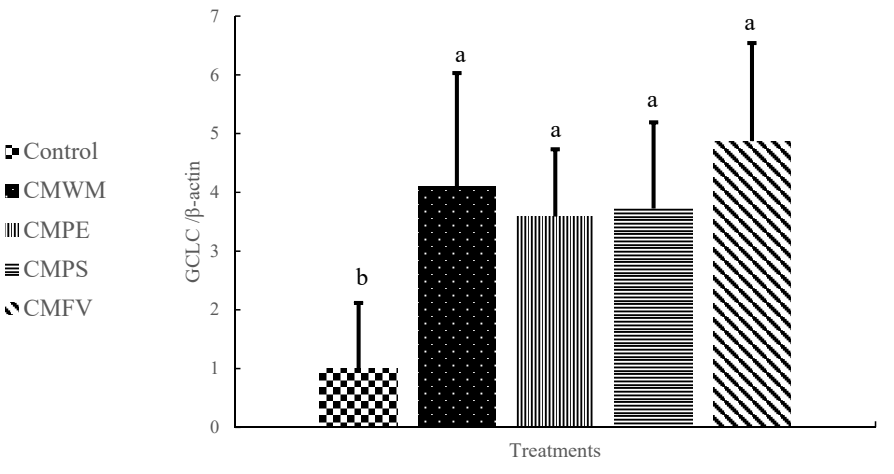

(F)

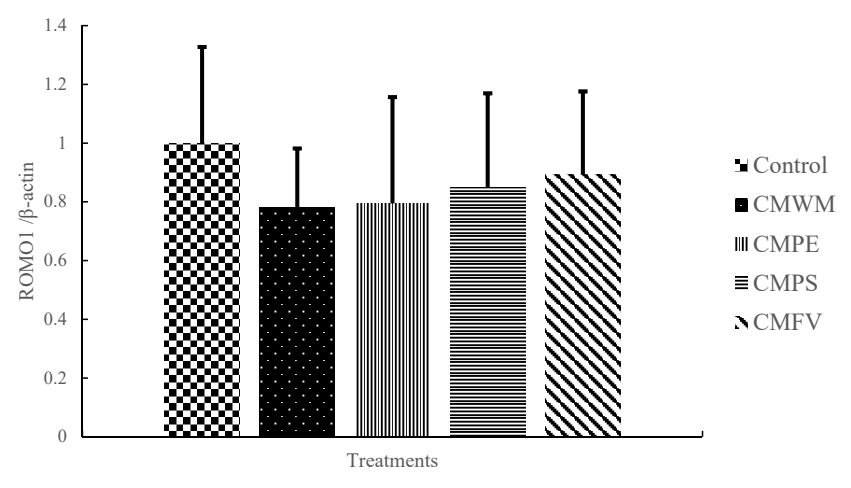

Figure 2. The expression levels of antioxidant-regulated mRNA in peripheral blood mononuclear cells (A) Keap1; (B) Nrf2; (C) HO-1; (D) GCLC; (E) NOX1; (F) ROM01. Keap1, Kelch like ECH associated protein 1; Nrf2, nuclear factor (erythroid-derived 2)-like 2; HO-1, heme oxygenase -1; GCLC, glutamate cysteine ligase catalytic subunit; NOX1, NADPH oxygenase 1; ROMO1, reactive oxygen species modulator protein 1; CMWM, 1\% Cordyceps militaris waster medium; CMPE, 0.5\% Cordyceps militaris waster medium+0.5\% Pleurotus eryngii stalk residues; CMPS, $0.5 \%$ Cordyceps militaris waster medium+0.5\% Pleurotus sajor-caju stalk residues; CMFV, $0.5 \%$ Cordyceps militaris waster medium+0.5\% Fammulina velutipes stalk residues. ${ }^{a-c}$ Means within the same row without common superscripts differ significantly.

\section{DISCUSSION}

Animals are typically subjected to a variety of stimuli that increase oxidative stress in the body. The stress makes some proteins, lipids, and even cell membranes and nucleic acids cause some diseases in farm [24-26]. Oxidative stress incompletely replicates DNA, inducing mutations or lesions [27]. The polysaccharides extracted from Cordyceps militaris have also confirmed to have free radical scavenging activity [28]. The Cordyceps militaris, Pleurotus eryngii, Pleurotus sajor-caju, and Fammulina velutipes are common mushrooms in Asia. These mushrooms have many functional ingredients, such as phenolic compounds, ergosterols, triterpenes, adenosine, flavonoids, polysaccharides, etc. These functional ingredients can improve antioxidant capacity [29], and their compositions in the medium and pedicles are similar to the sporocarp.

The results show that mushroom stalk residues improved body weight gain and FCR, especially in the group CMWM. The present study is similar to Han et al [30]. Lipopolysaccharide (LPS) causes the integrity of the gut barrier incomplete 
and makes the energy support the immune system, causing lower growth performance [31]. Won et al [32] point out that the administration of $1 \%, 5 \%$, and $10 \%$ of ethanolic extracts of cultured mycelia of Cordyceps militaris can effectively reduce $\alpha$-iNOS produced by stimulation of RAW 264.7 cells with LPS. It is speculated that the mushroom stalk residues can improve intestinal health, reduce inflammatory response.

Intestinal epithelial tissue has a various protein structure that blocks exogenous toxins into the body, toxins intruding into the body will cause an immune response such as macrophages deactivation and detoxification [33]. It shows that the integrity of the intestine is very important for the health and growth of animals. In addition to separating in vitro and in vivo, the gastro intestinal tract (GIT) can also absorb nutrients such as proteins, sugars, lipids, and various vitamins and minerals from the cavity [31]. The CMWM group can increase the villus height and crypt depth ratio of the jejunum, which can increase the surface area of the villus and improve the absorption of nutrients [34]. The deeper the crypt is, the more the intestinal cells proliferate and the more energy is consumed, which is unpleasant in broilers. The intestinal cells will compensate growth to suppress stress, and crypt depth is one of the indicators of whether the intestine is in an abnormal physiological state. The results show that the crypt depth of the CMPS group was lower than the control group. Thus, it can be speculated that mushroom stalk residues have the ability to reduce stress from environment. If fiber in the diet is insufficient, then gut microbiota resorts to host-secreted mucus glycoproteins as a nutrient source, leading to erosion of the colonic mucus barrier [35]. The mushroom stalk residues can increase the fiber content in feed, reduce erosion of intestinal mucin glycoprotein by microbial, and indirectly reduce stress in the intestine.

There are specific microbes that are stable in the intestines, which have a very complex microbial ecology especially in the cecum [36]. The intestinal microbes can be important in the health of the host. In order to maintain health, it is necessary to improve the intestinal microbes. In recent years, probiotics or prebiotics have been used to improve intestinal microbes [36,37]. It was found that the mushroom stalk residues could increase the number of Lactobacillus spp. and reduce Coliform amount in the data, but there are no significant differences in each group. It is similar to the experiment result of feeding broiler chickens with Cordyceps water extract that promoted the growth of Lacribacillus and reduced Salmonella and Escherichia coli in the intestine [38]. It may be due to the antibacterial activity of some polysaccharides that are not easily absorbed and can improve the intestinal health $[36,39,40]$.

There is a dynamic redox system in animals. Free radicals or ROS are generated during normal metabolism. There are two kinds of antioxidant systems in the cells in order to re- move these oxidizing substances: i) a non-enzymatic system and ii) an enzymatic system. The former includes glutathione, which can directly remove ROS, and the latter (including catalase) can reduce hydrogen peroxide to hydrogen oxide [25]. The anti-oxidation pathway of Nrf2/Keap1 belongs to the non-enzymatic system. There is no activity when Nrf2 is bound with Keap1 in the cytoplasm. Keap1 will be separated from Nrf2 after phosphating. Nrf2 will enter the nucleus and form a dimer with Maf protein and will react with the antioxidant responsive element and regulate antioxidant genes such as GCLC and HO-1 [41]. Glutamate cysteine ligase consists of heavy chain GCLC and light chain glutamate-cysteine ligase modulatory; among them, GCLC is the site of catalytic antioxidant activity [42]. HO-1 is the rate-limiting enzyme of heme metabolism, which can catalyze the cleavage of heme into biliverdin (BV) and further be converted into bilirubin (BR) by biliverdin reductase on cytoplasmic [43]. The cycles of $\mathrm{BR}$ and $\mathrm{BV}$ can reduce the risk of excessive $\mathrm{H}_{2} \mathrm{O}_{2}$ on animals [44]. The NADPH oxygenase 1 (NOX1) family and reactive oxygen species modulator protein 1 (ROMO1) are proteins that are produced in normal physiology. The former is NADPH oxidase, and the latter is a protein produced in the electron transport chain. NOX-1 causes some lipid peroxidation and even endothelial damage [45]. ROMO1 is a regulator of ROS in mitochondria, which causes oxidative stress and apoptosis of cells [46]. The results show that the mushroom stalk residues can enhance the Nrf2 pathway, probably because phenols can activate Nrf2 [47], but NOX1 and ROMO1 exhibit no significant difference.

\section{CONCLUSION}

Based on the above results, CMWM (1\%) has the best effect on improving intestinal health and growth performance of broilers and can enhance the antioxidant capacity through the Nrf2 and Keap1 pathways in order to show resistance to stress compare with other groups. The Cordyceps militaris waster medium has the potential to be developed as a feed additive in the future.

\section{CONFLICT OF INTEREST}

We certify that there is no conflict of interest with any financial organization regarding the material discussed in the manuscript.

\section{ACKNOWLEDGMENTS}

The authors thank the Taiwan Agricultural Research Institute (Council of Agriculture), the Ministry of Science and Technology (MOST 109-2321-B-005-016-) and the iEGG and Animal Biotechnology Center from The Feature Areas Re- 
search Center Program within the framework of the Higher Education Sprout Project by the Ministry of Education (MOE) in Taiwan for supporting this study.

\section{REFERENCES}

1. Lykkesfeldt J, Svendsen O. Oxidants and antioxidants in disease: oxidative stress in farm animals. Vet J 2007;173:50211. https://doi.org/10.1016/j.tvjl.2006.06.005

2. Attia YA, Al-Harthi MA, El-Shafey AS, Rehab YA, Kim WK. Enhancing tolerance of broiler chickens to heat stress by supplementation with vitamin $\mathrm{E}$, vitamin $\mathrm{C}$ and/or probiotics. Ann Anim Sci 2017;17:1155-69. https://doi.org/10.1515/ aoas-2017-0012

3. Attia YA, Allakany HF, Abd Al-Hamid AE, Al-Saffar AA, Hassan RA, Mohamed NA. Capability of different nonnutritive feed additives on improving productive and physiological traits of broiler chicks fed diets with or without aflatoxin during the first 3 weeks of life. J Anim Physiol Anim Nutr 2013;97:754-72. https://doi.org/10.1111/j.1439-0396. 2012.01317.x

4. Sigolo S, Khazaei R, Seidavi A, Ayasan T, Gallo A, Prandini A. Effects of supra-nutritional levels of vitamin $\mathrm{E}$ and vitamin $\mathrm{C}$ on growth performance and blood parameters of Japanese quails. Ital J Anim Sci 2019;18:140-6. https://doi.org/10.1080/ 1828051X.2018.1500496

5. Chattopadhyay MK. Use of antibiotics as feed additives: a burning question. Front Microbiol 2014;5:334. https://doi. org/10.3389/fmicb.2014.00334.

6. Victor VM, Apostolova N, Herance R, Hernandez-Mijares A, Rocha M. Oxidative stress and mitochondrial dysfunction in atherosclerosis: mitochondria-targeted antioxidants as potential therapy. Curr Med Chem 2009;16:4654-67. https:// doi.org/10.2174/092986709789878265

7. Yin MC. Anti-glycative potential of triterpenes: a minireview. Biomedicine 2012;2:2-9. https://doi.org/10.1016/j. biomed.2011.12.001

8. Hassan O, Fan LS. The anti-oxidation potential of polyphenol extract from cocoa leaves on mechanically deboned chicken meat (MDCM). LWT - Food Sci Technol 2005;38:315-21. https://doi.org/10.1016/j.lwt.2004.06.013

9. Das SK, Masuda M, Sakurai A, Sakakibara M. Medicinal uses of the mushroom Cordyceps militaris: current state and prospects. Fitoterapia 2010;81:961-8. https://doi.org/10.1016/ j.fitote.2010.07.010

10. Shin S, Park Y, Kim S, et al. Cordyceps militaris enhances $\mathrm{MHC}$-restricted antigen presentation via the induced expression of MHC molecules and production of cytokines. Immune Netw 2010;10:135-43. https://doi.org/10.4110/in.2010.10. 4.135

11.Lee TT, Ciou JY, Chiang CJ, Chao YP, Yu B. Effect of Pleurotus eryngii stalk residue on the oxidative status and meat quality of broiler chickens. J Agric Food Chem 2012;60:11157-63. https://doi.org/10.1021/jf302740h

12.Lai LP, Lee MT, Chen CS, Yu B, Lee TT. Effects of co-fermented Pleurotus eryngii stalk residues and soybean hulls by Aureobasidium pullulans on performance and intestinal morphology in broiler chickens. Poult Sci 2015;94:2959-69. https://doi. org/10.3382/ps/pev302

13. Safari O, Sarkheil M. Dietary administration of eryngii mushroom (Pleurotus eryngii) powder on haemato-immunological responses, bactericidal activity of skin mucus and growth performance of koi carp fingerlings (Cyprinus carpio koi). Fish Shellfish Immunol 2018;80:505-13. https://doi.org/10. 1016/j.fsi.2018.06.046

14. Chirinang P, Intarapichet KO. Amino acids and antioxidant properties of the oyster mushrooms, Pleurotus ostreatus and Pleurotus sajor-caju. Sci Asia 2009;35:326-31. https://doi.org/ 10.2306/scienceasia1513-1874.2009.35.326

15. Nithya R, Ragunathan R. Synthesis of silver nanoparticle using Pleurotus sajor caju and its antimicrobial study. Dig J Nanomater Biostruct 2009;4:623-9.

16. Mahfuz S, Song H, Liu Z, et al. Effect of golden needle mushroom (Flammulina velutipes) stem waste on laying performance, calcium utilization, immune response and serum immunity at early phase of production. Asian-Australas J Anim 2018;31:705-11. https://doi.org/10.5713/ajas.17.0787

17. Wang CL, Chiang CJ, Chao YP, Yu B, Lee TT. Effect of Cordyceps militaris waster medium on production performance, egg traits and egg yolk cholesterol of laying hens. J Poult Sci 2015; 52:188-96. https://doi.org/10.2141/jpsa.0140191

18. Ogunlana OE, Ogunlana OO, Farombi EO. Assessment of the scavenging activity of crude methanolic stem bark extract of Newbouldia laevis on selected free radicals. Adv Nat Appl Sci 2008;2:249-54.

19. Morel I, Cillard J, Lescoat G, et al. Antioxidant and free radical scavenging activities of the iron chelators pyoverdin and hydroxypyrid-4-ones in iron-loaded hepatocyte cultures: comparison of their mechanism of protection with that of desferrioxamine. Free Radic Biol Med 1992;13:499-508. https://doi.org/10.1016/0891-5849(92)90144-6

20. NRC. Nutrient Requirements of Poultry. 9th rev. ed. Washington, DC, USA: National Academy Press; 1994.

21.Ramlucken U, Ramchuran SO, Moonsamy G, Lalloo R, Thantsha MS, Rensburg CJ. A novel Bacillus based multistrain probiotic improves growth performance and intestinal properties of Clostridium perfringens challenged broilers. Poult Sci 2020;99:331-41. https://doi.org/10.3382/ps/pez496

22.AOAC. Official methods of analysis. 17th ed. Washington, DC, USA: Association of Official Analytical Chemists; 2000.

23. Yamaguchi T, Takamura H, Matoba T, Terao J. HPLC method for evaluation of the free radical-scavenging activity of foods by using 1, 1-diphenyl-2-picrylhydrazyl. Biosci Biotechnol Biochem 1998;62:1201-4. https://doi.org/10.1271/bbb.62.1201

24. Attia YA, Abd El Hamid AE, Ismaiel AM, et al. Nitrate detoxi- 
fication using antioxidants and probiotics in the water for rabbits. Rev Colomb Cienc Pecu 2018;31:130-8. https://doi. org/10.17533/udea.rccp.v31n2a06

25. Attia YA, Abd El Hamid AE, Ismaiel AM, El-Nagar A. The detoxication of nitrate by two antioxidants or a probiotic, and the effects on blood and seminal plasma profiles and reproductive function of New Zealand White rabbit bucks. Animal 2013;7:591-601. https://doi.org/10.1017/S175173 1112002054

26. Senay S, Islim P, Tugay A. Supplementation of natural antioxidants to reduced crude protein diets for Japanese quails exposed to heat stress. Braz J Poult Sci 2019;21:1-14. https:// doi.org/10.1590/1806-9061-2017-0694

27. Jung KA, Kwak MK. The Nrf2 system as a potential target for the development of indirect antioxidants. Molecules 2010;15: 7266-91. https://doi.org/10.3390/molecules15107266

28. Yu R, Yang W, Song L, Yan C, Zhang Z, Zhao Y. Structural characterization and antioxidant activity of a polysaccharide from the fruiting bodies of cultured Cordyceps militaris. Carbohydr Polym 2007;70:430-6. https://doi.org/10.1016/j. carbpol.2007.05.005

29. Smina TP, De S, Devasagayam TPA, Adhikari S, Janardhanan KK. Ganoderma lucidum total triterpenes prevent radiationinduced DNA damage and apoptosis in splenic lymphocytes in vitro. Mutat Res Genet Toxicol Environ Mutagen 2011;726: 188-94. https://doi.org/10.1016/j.mrgentox.2011.09.005

30. Han JC, Qu HX, Wang JG, et al. Effects of fermentation products of Cordyceps militaris on growth performance and bone mineralization of broiler chicks. J Appl Anim Res 2015;43: 236-41. https://doi.org/10.1080/09712119.2014.928630

31.Mani V, Weber TE, Baumgard LH, Gabler NK. Growth and development symposium: endotoxin, inflammation, and intestinal function in livestock. J Anim Sci 2012;90:1452-65. https://doi.org/10.2527/jas.2011-4627

32. Won SY, Park EH. Anti-inflammatory and related pharmacological activities of cultured mycelia and fruiting bodies of Cordyceps militaris. J Ethnopharmacol 2005;96:555-61. https://doi.org/10.1016/j.jep.2004.10.009

33. Buttenschoen K, Radermacher P, Bracht H. Endotoxin elimination in sepsis: physiology and therapeutic application. Langenbecks Arch Surg 2010;395:597-605. https://doi.org/ 10.1007/s00423-010-0658-6

34. Baurhoo B, Phillip L, Ruiz-Feria CA. Effects of purified lignin and mannan oligosaccharides on intestinal integrity and microbial populations in the ceca and litter of broiler chickens. Poult Sci 2007;86:1070-8. https://doi.org/10.1093/ps/86.6.1070

35. Desai MS, Seekatz AM, Koropatkin NM, et al. A dietary fiberdeprived gut microbiota degrades the colonic mucus barrier and enhances pathogen susceptibility. Cell 2016;167:133953. https://doi.org/10.1016/j.cell.2016.10.043

36. Guo FC, Williams BA, Kwakkel RP, et al. Effects of mushroom and herb polysaccharides, as alternatives for an antibiotic, on the cecal microbial ecosystem in broiler chickens. Poult Sci 2004;83:175-82. https://doi.org/10.1093/ps/83.2.175

37. Attia YA, Ellakany HF, Abd El-Hamid AE, Bovera F, Ghazaly SA. Control of Salmonella enteritidis infection in male layer chickens by acetic acid and/or prebiotics, probiotics and antibiotics. Arch Geflugelk 2012;76:239-45.

38. Koh JH, Suh HJ, Ahn TS. Hot-water extract from mycelia of Cordyceps sinensis as a substitute for antibiotic growth promoters. Biotechnol Lett 2003;25:585-90. https://doi.org/10.1023/ A:1022893000418

39. Attia YA, Abd Al-Hamid AE, Allakany HF, Al-Harthi MA, Mohamed NA. Necessity of continuing of supplementation of non-nutritive feed additive during days 21-42 of age following three weeks of feeding aflatoxin to broiler chickens. J Appl Anim Res 2016;44;87-98. https://doi.org/10.1080/097 12119.2015.1013964

40.Celik K, Uluocak AN, Ayasan T, Doran F, Ozturkcan O. The effects of different levels of mycotoxin (AFB1) on Japanese quail's performance and its histopatholigycal characteristics. In: Proceedings of the VIV Poultry YUTAV'99 Uluslararasi Tavukçuluk Fuari ve Konferansi; 1999 Jun 3-6: Istanbul, Turkey: YUTAV’99 Bildiriler Kitab; 1999. pp. 222-30.

41.Sahin K, Orhan C, Smith MO, Sahin N. Molecular targets of dietary phytochemicals for the alleviation of heat stress in poultry. Worlds Poult Sci 2013;69:113-24. https://doi.org/10. 1017/S004393391300010X

42.Dickinson DA, Levonen AL, Moellering DR, et al. Human glutamate cysteine ligase gene regulation through the electrophile response element. Free Radic Biol Med 2004;37: 1152-9. https://doi.org/10.1016/j.freeradbiomed.2004.06. 011

43. Araujo JA, Zhang M, Yin F. Heme oxygenase-1, oxidation, inflammation, and atherosclerosis. Front Pharmacol 2012; 3:119. https://doi.org/10.3389/fphar.2012.00119

44.McDonagh AF. The biliverdin-bilirubin antioxidant cycle of cellular protection: missing a wheel? Free Radic Biol Med 2010;49:814-20. https://doi.org/10.1016/j.freeradbiomed. 2010.06.001

45.Stocker R, Keaney JF. Role of oxidative modifications in atherosclerosis. Physiol Rev 2004;84:1381-478. https://doi. org/10.1152/physrev.00047.2003

46.Lee SB, Kim JJ, Kim TW, Kim BS, Lee MS, Yoo YD. Serum deprivation-induced reactive oxygen species production is mediated by Romo1. Apoptosis 2010;15:204-18. https://doi. org/10.1007/s10495-009-0411-1

47.Arredondo F, Echeverry C, Abin-Carriquiry JA, et al. After cellular internalization, quercetin causes Nrf2 nuclear translocation, increases glutathione levels, and prevents neuronal death against an oxidative insult. Free Radic Biol Med 2010; 49:738-47. https://doi.org/10.1016/j.freeradbiomed.2010. 05.020 